\title{
Demand for Indoor Air Pollution Abatement Interventions
}

\author{
Helen Hoka Osiolo ${ }^{1}$ Peter Kimuyu ${ }^{2}$
}

Received: 30 August 2016 / Accepted: 27 July 2017 / Published online: 5 September 2017

(C) Springer International Publishing AG 2017

\begin{abstract}
This paper investigates the demand for indoor air pollution (IAP) abatement interventions where the levels of IAP are captured by the different household cooking energy. Heckman's sample selection model is applied on data drawn from the Kenya Integrated Household Budget Survey. The results show that geographical location, type of household energy used, cooking place/area, type of dwelling, income and presence or lack of a chimney are key factors that shape the demand for IAP abatement interventions. In order to reduce IAP and improve health outcomes, the government could introduce policies that enhance use of modern forms of energy, improved stoves and chimney as IAP abatement interventions. There is also need to focus on increasing people's income, educational levels and encouraging creation of own improved stove designs that integrate technology with local culture.
\end{abstract}

Keywords Demand · Indoor air pollution · Heckman's sample selection model $\cdot$ Energy sources

Helen Hoka Osiolo

helen.hoka@gmail.com; hosiolo@kippra.or.ke

Peter Kimuyu

pkimuyu@uonbi.ac.ke

1 Infrastructure and Economic Service Division, Kenya Institute of Public Policy Research and Analysis, P.O. Box 56445-00200, Nairobi, Kenya

2 School of Economics, University of Nairobi, P.O. Box 30197-00100, Nairobi, Kenya

\section{Introduction}

\section{Background on Indoor Air Pollution from Household Energy Use}

Indoor air pollution (IAP) from household energy use affects household overall welfare, since it is known to be associated with poor health outcomes that have adverse consequences on an individual's productivity. Interventions aimed at reducing IAP correspondingly improve health, by for example diminishing the burden of respiratory diseases (Diaz 2008). In rural Guatemala, use of improved ${ }^{1}$ stoves (plancha) significantly reduced the number of respiratory symptoms, especially the prevalence of wheezing, headache and eye discomfort and, after 18 months of use, such improved stoves were also related with significantly better self-rated health (Pant 2007). IAP abatement interventions have also been linked to reduced mortality rates (Zuk et al. 2006). Apart from health benefits, use of plancha also reduces firewood consumption, which is an environmental benefit with expected positive welfare effects as fewer resources are assigned to medical expenses and firewood collection increasing household productivity (Adrianzén 2010).

One of the intended benefits of using the plancha is to reduce wood fuel consumption. However, the consumption of wood fuel in Kenya tells a different story. For example the Economic Outlook report of 2016 by Deloitte show that the current wood fuel demand in Kenya is close to 3.5 million

\footnotetext{
$\overline{1}$ The development of improved stoves rely on the work of Winiarski and Evans whose main objectives were to improve health from better indoor air quality, save on cooking time, increasing environmental gains through reduced emissions and deforestation. See Winiarski (2005); Baldwin and Winiarski (2005); and Lanto and Leslie (2006).
} 
tonnes per year, while supply is at 1.5 million tonnes per year. This is not only unsustainable but has led to excessive deforestation and destruction of animal habitat. The high demand of wood fuel may suggest that there is low adoption of plancha in Kenya. The use of fossil fuels, as an alternative to wood fuels may seem appropriate to addressing energy scarcities in Kenya. This may not be the case. For instance, the Intergovernmental Panel on Climate Change (IPCC) Synthesis Report of 2014 indicates that in order to limit warming to $2{ }^{\circ} \mathrm{C}$, the world needs to make a rapid shift from fossil fuels to clean energy.

Ballard-Tremeer and Mathee (2000) discussed three different technical interventions that can reduce IAP. First, producing less smoke (targeting source of pollution) by use of improved stoves and fuels. Second, getting smoke out of the indoor (living) environment via chimneys, windows, doors and modifying kitchen design. Lastly, reducing exposure to smoke (targeting behavioural changes) by reducing cooking time, fuel drying, using pot lids to conserve heat, proper maintenance of stoves and related appliances and keeping children away from smoke in other rooms.

Although there are numerous interventions that can be adopted, there is inconclusive evidence on which ones are the most effective. However, use of modern ${ }^{2}$ energy is considered most effective in terms of abating IAP, and it was ranked highly as a long-term project of about 15-30 years by Goldemberg (2000) as poor households can neither afford the fuel nor other complementary upfront costs such as gas and electric cookers, gas (LPG) cylinders, cylinder valves and pipes. It is also important to note that when compared to other cooking energy sources such as improved combustion, if gas is unavailable in 20 years as predicted by International Energy Association (IEA) and Association for Peak Oil and Gas (ASPO), then cooking with gas will not be a long-term solution.

Since biomass is a fuel choice for many poor households, the use of improved stoves is likely to be more effective than redesigning the kitchen location (Department for International Development-DFID 1999). However, this is considered a short-term measure (Goldemberg 2000). The use of chimney or hoods provides consistent exit for smoke, and it is not dependent on improved stoves (Bates and Doig 2001). The use of chimney is regarded as a medium-term measure by WHO (2000). Ezzati and Kammen (2002), Ezzati (2002)

\footnotetext{
2 The term "modern" as used in previous studies refers to use of electricity and modern cooking solutions (see World Bank 2011). According to World Bank, modern cooking solutions incorporates the use of modern cooking fuels [such as natural gas, liquefied petroleum gas (LPG) and biogas] and advanced cook stoves (that have higher combustion efficiency, clean, safe and are manufactured in either workshops or factories). In this paper the term "modern energy" refers to the use of electricity and LPG for cooking.
}

and Hosier and Dowd (1987) conclude that although the benefits of adopted interventions may be known, as illustrated by varying levels of success of different stove programmes, the factors that motivate households to adopt an intervention or suite of interventions and the required institutions are not clear.

The paper focuses on Kenya as one of the countries in the East Africa sub-region in sub-Saharan Africa that relies heavily on traditional biomass for cooking with about 15,000 deaths linked to IAP (Lambe et al. 2015). However, adoption of IAP abatement interventions remains dismal.

For this reason, the paper seeks to find out why households are not adopting interventions aimed at abating exposure to IAP, despite their positive implications for welfare. Specifically, the objectives addressed in this paper are to examine the demand for IAP abatement intervention and examine drivers of adoption of IAP abatement interventions.

This paper makes three contributions to the literature on the demand for IAP abatement interventions. First, it provides empirical evidence from Kenya on the demand for IAP abatement interventions. Three categories of IAP abatement interventions are identified, namely: the use of improved stove, modern energy and chimney (ventilation intervention). This categorisation is important since the demand for abatement interventions may differ among the three IAP abatement interventions. Second, this paper uses the Heckman (selection) model in order to address the potential sample selection bias associated with substantive dependent variable of interest. Third, the paper is among the first to estimate the demand for chimney as one of the key IAP abatement interventions.

The rest of the paper is organised as follows. In "Literature Review", we discuss the literature review on the demand for IAP abatement interventions. The methodology, data and description of variables are the subject matter of "Methodology". The results are then presented in "Results and Discussion" and in "Conclusions and Policy Implications" we conclude and make policy suggestions.

\section{Household Cooking Energy}

Historically, Kenyan households have relied on biomass as the main source of cooking energy, but with advances in technology and economic growth, LPG, electricity and biogas have been adopted by about $7 \%$ of the households (GoK 2010).

The 2005/2006, Kenya Integrated Household Budget Survey (KIHBS) shows that firewood is the most common source of cooking energy accounting for $68.3 \%$ (Table 1) of the total household energy consumed (GoK 2006). Rural households are the major consumers $(87.7 \%)$ of firewood. The second major form of fuel consumed by households is charcoal, representing $13.3 \%$ of the total household energy 
Table 1 Percentage distribution of the population by main source of cooking fuel. Source: GoK (2006) and GoK (2010)

\begin{tabular}{lllllrr}
\hline Data source & Firewood & Grass & Kerosene & Electricity & LPG & Charcoal \\
\hline National (\%)_KIHBS, 2006 & 68.3 & 0.1 & 13.2 & 0.6 & 3.5 & 13.3 \\
National (\%)_KDHS, 2010 & 63.3 & 1.2 & 8.1 & 0.5 & 6.5 & 18.7 \\
Rural (\%)—KIHBS, 2006 & 87.7 & 0.1 & 2.7 & 0.2 & 0.7 & 7.7 \\
Rural (\%)_KDHS, 2010 & 83.3 & 1.4 & 1.5 & 0.1 & 1.2 & 18.7 \\
Urban (\%)-KIHBS, 2006 & 10 & 0.2 & 44.6 & 1.8 & 11.9 & 30.2 \\
Urban (\%)_KDHS, 2010 & 6.1 & 0.8 & 26.9 & 1.6 & 21.7 & 10.8 \\
\hline
\end{tabular}

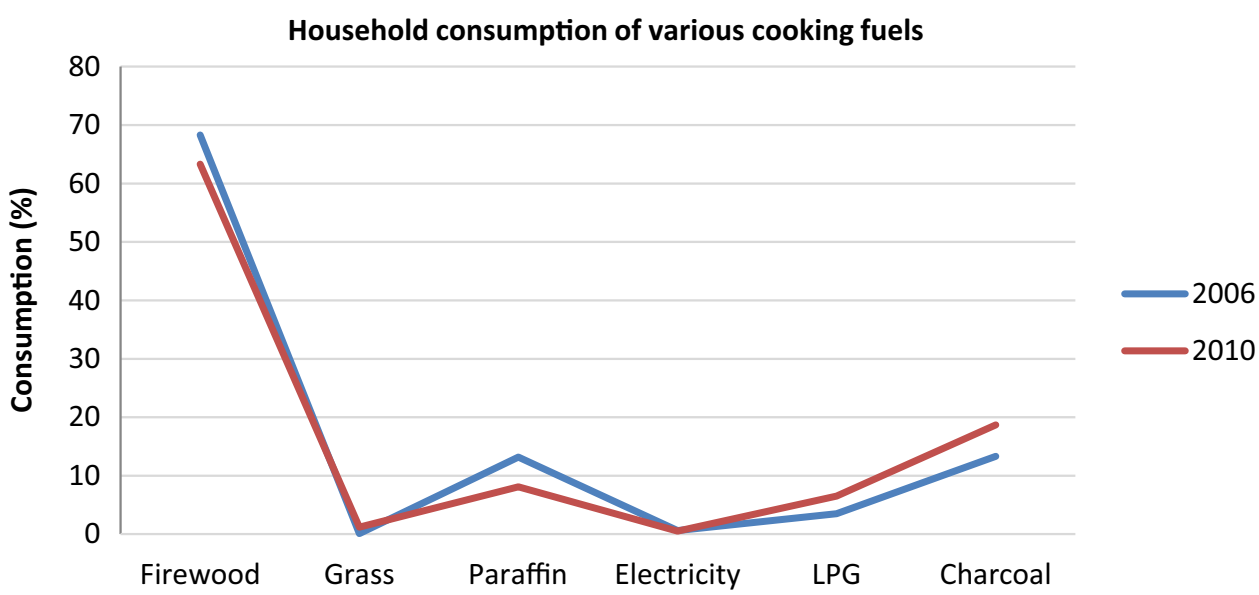

Fig. 1 Household consumption of various cooking fuels, 2006 and 2010. Source GoK (2006) and GoK (2010) consumed. This is closely followed by paraffin/kerosene at $13.2 \%$, with the urban households consuming about $44.6 \%$.

At the national level, LPG is the most consumed modern fuel among households estimated at 3.5\%, compared to electricity which accounts for $0.6 \%$. The urban population is the major consumer of modern energy with 11.9 and $1.8 \%$ for LPG and electricity, respectively.

The Kenya Demographic and Health Survey (KDHS) shows that the highest consumed household energy in 2010 was firewood representing $63.3 \%$ of the total household energy at the national level, and 83.3 and $6.1 \%$ in rural and urban areas, respectively. The least consumed was electricity accounting for $0.5 \%$ at the national level, while 0.1 and $1.6 \%$ was consumed by rural and urban population, respectively. There is no evidence of significant difference in household energy consumption between 2006 and 2010 as observed in Fig. 1.

Though Kenyan households also consider cooking using solar, the two data sources (KIHBS and KDHS) do not provide this data. However, KIHBS provides data on solar energy as option for lighting energy sources. A number of advocacy groups including the Solar Cookers International are promoting the use of solar cooker with intentions to reduce IAP, save forests and enhance women productivity and children education by saving time required for fetching wood fuels.

\section{Literature Review}

The energy ladder and fuel stacking models explain how households behave with regard to energy use and have also been used to explain the demand for fuel and fuel stove appliance as interventions for reducing IAP (Masera et al. 2000; Adol-Agyarko 2009; Duflo et al. 2008).

The energy ladder model embodies a three-step phase where households are observed to switch or transit from use of traditional energy (firewood and charcoal) to modern energy (LPG and electricity) as incomes rise (Leach 1992). This model has also been used to rank cooking energy with regard to the level of IAP, development of technology, safety and ease of use (Barnes 2005). Smith (1987) observes that as fuels become safer, they also increase in cost. Jebaraj and Iniyan (2006) indicate that apart from the income factor that comes out strongly in the energy models, culture; social and behavioural factors are also important in explaining household energy choices.

They are a number of shortcomings of the energy ladder model. One, it assumes that incomes impede the usage of modern fuels and hence the widely observed usage of fuel wood. Hiemstra-van der Horst and Hovorka (2008) and Hosier and Kipondya (1993) show that in developing countries, fuel wood is consumed by both low- and high-income populace. In addition to the notion that fuel wood is a fuel of the poor (Leach 1992) is flawed, consumer preferences and lifestyle concerns explain the consumption of the fuel 
wood instead of income. Two, consumers' choice of energy is influenced by culture, social and behavioural factors in addition to income and consumer preferences and lifestyle (Jebaraj and Iniyan 2006). Three, the energy ladder model assumes a simple and complete switch of energy fuels. However, households in developing countries consume more than one fuel and their energy behaviour is well described by energy stack models (Masera et al. 2000). The fuel stacking model describes how households are observed to use multiple fuels, rather than completely switching to use modern energy (Masera et al. ibid).

The consumer theory where household decision-making approach is used to explain the demand for IAP abatement interventions have mainly been applied to improved stoves and modern energy adoption interventions as discussed by Gebreegziabher et al. (2010) and Mekonnen and Kohlin (2008). Discussions focusing on household decision-making decisions on house ventilation/chimney are limited and largely ignored. Identification of key factors and their size of magnitude in terms of impact is possible through use of consumer theory approach. However, the application of this approach does not provide concrete figures of the cost and benefits expected or derived.

The demand for IAP abatement interventions can also be explained by willingness to pay concept (Larson and Rosen 2002). The economic rationale for this is that the demand for IAP abatement intervention by households should equal the willingness to pay for the IAP abatement interventions. For instance, if the households willingness to pay captured by perceived net gains is larger than the cost, then adoption of the IAP abatement intervention will take place. Larson and Rosen (ibid) therefore concludes that for the case of developing countries, the household's willingness to pay for the existing IAP abatement interventions is lower than the estimated cost. The advantage of using expressed willingness to pay is that it can be applied to analyse the economic value of both marketed and non-marketed goods and services. The method may erroneously assume that people understand the good or service in question and will reveal their preferences in a "contingent" market just as in a real market.

The demand for IAP abatement intervention is also explained by the welfare impacts of different policy intervention scenarios (Zhang 2009). If the welfare impact of a certain IAP abatement intervention is positive, then it is expected that household demand for the intervention would increase; however, the magnitude of this increase may depend on the policy intervention instituted. In order to measure the welfare impact, discrete choice models have been widely applied using the compensating variation approach (Zhang, ibid).

Policy simulation is also another concept that seeks to explain the demand for IAP abatement interventions. Edwards and Langpap (2008) explain how the policy simulation approach can evaluate different IAP policy interventions and propose policies that can accelerate adoption of IAP abatement intervention. IAP interventions with maximum benefits to households are identified after carrying out simulation process. Policies are then put in place to encourage wider adoption of the identified IAP interventions. Policy simulation approach heavily relies on the assumptions adopted. Plausible assumptions that depict the reality are seldom achieved.

Household demand for various interventions has been explained on the basis of perceived benefits and costs (Larson and Rosen 2002; Pant 2007). However, in addition to economic reasons, social, culture, behavioural and environmental factors may explain why an intervention is adopted or not adopted.

There is considerable information on the use of improved stoves and modern energy as potential intervention for reducing IAP (Gebreegziabher et al. 2010; Jaggernath 2013; Masera et al. 2000; Oudejans 2011). However, little is known about the ventilation and improvements in kitchen design interventions, and their drivers. In addition, factors that motivate households to adopt any intervention or suite of interventions and the required institutions are still unclear, despite known benefits of such interventions (Ezzati and Kammen 2002; Ezzati 2002; Barnes et al. 1994; Hosier and Dowd 1987).

This study adds to existing literature by now determining the demand for IAP abatement interventions. In addition to common interventions (use of modern energy and improved stoves), we extend the analysis by including the demand for chimney as a ventilation facility. Apart from the benefits and costs, other factors such as kitchen type/location of cooking area, culture, social and economic characteristics that influence the choice of particular IAP interventions are considered. The study also makes use of the consumer theory in order to identify and model the demand for IAP abatement interventions.

Knowing the factors that influence adoption of different interventions allows accurate forecast of the demand for the different interventions and modification of technology that widens the adoption rate of the different interventions.

\section{Methodology}

\section{Analytical Model}

\section{Theoretical Model}

The paper uses the indoor air quality production function that has been modified from the health production function based on Grossman (1972) and applied by Gupta (2006); Adhikari (2012); and Brandt and Hanemann (2003). Demand 
functions for averting activities are derived. Averting activities such as adopting improved cooking stove, modifying the living environment and switching to modern energy are households' averting behaviour aimed at reducing IAP.

The household maximises utility function defined as:

$U=U(X, L, I)$,

where $X$ is consumption of goods; $L$, is leisure; and $I$, IAP. The household derives utility from consumption of goods and leisure, while IAP results in disutility. The household produces unpolluted (clean) air by combining averting activities (such as adopting improved cooking stoves, modifying living environment characteristics and use of modern energy) with other socio-economic factors. The indoor air quality function is:

$I=I(B, C, D, Z)$,

where $I$ is a measure of IAP; $B$, adopting improved cooking stoves; $C$, modifying living environment; $D$, switching to the use modern energy; and $Z$, social economic factors.

The household budget constraint is specified as:

$Y+W(T-L-\propto I)=P_{\mathrm{x}} X+P_{\mathrm{b}} B+P_{\mathrm{c}} C+P_{\mathrm{d}} D$,

where $Y$ is non-wage income; $W$, wage rate; $(T-L-\propto I)$ time spent at work ( $T$ is total time; $L$, is leisure time; and, $\propto I$ is lost days of work due to self-nursing/attending to child with respiratory infection caused by IAP); $X$, consumption goods; and $B, C$ and $D$ are as defined above. $P_{\mathrm{b}}$ is the price per unit of adopting improved cooking stove; $P_{\mathrm{c}}$, price per unit of modifying living environment; $P_{\mathrm{d}}$, price per unit of switching to use modern energy; and $P_{\mathrm{x}}=1$, price of the bundle of consumption goods normalised to one.

The household maximises the utility function (Eq. 3.1) with respect to $X, L, B, C$ and $D$ subject to the budget constraint (Eq. 3.3). The household utility maximisation problem is:

$\operatorname{Max} U=U[X, L, I(B, C, D, Z)]$

Subject to $X+P_{\mathrm{b}} B+P_{\mathrm{c}} C+P_{\mathrm{d}} D=Y+W(T-L)-W \propto I(B, C, D, Z)$

The langrangian function, where $\lambda$ is the Lagrangian multiplier: $\frac{\partial U}{\partial B}=\lambda\left[W \propto \frac{\partial I}{\partial B}+P_{\mathrm{b}}\right]$

$\frac{\partial U}{\partial C}=\lambda\left[W \propto \frac{\partial I}{\partial C}+P_{\mathrm{c}}\right]$

$\frac{\partial U}{\partial D}=\lambda\left[W \propto \frac{\partial I}{\partial D}+P_{\mathrm{d}}\right]$

Simplifying and re-arranging Eqs. (3.6c), (3.6d) and (3.6e) yields:

$\frac{\partial X}{\partial I}=W \propto+\frac{P_{\mathrm{b}}}{\partial I / \partial B}$

$\frac{\partial X}{\partial I}=W \propto+\frac{P_{\mathrm{c}}}{\partial I / \partial C}$

$\frac{\partial X}{\partial I}=W \propto+\frac{P_{\mathrm{d}}}{\partial I / \partial D}$

The solution to the utility maximisation problem yields these demand functions for averting activities that is adopting improved cooking stoves, modifying living environment and switching to use modern energy, respectively.

$B=B\left(P_{\mathrm{b}}, P_{\mathrm{c}}, P_{\mathrm{d}}, W, Y+W T, Z\right)$

$C=C\left(P_{\mathrm{b}}, P_{\mathrm{c}}, P_{\mathrm{d}}, W, Y+W T, Z\right)$

$D=D\left(P_{\mathrm{b}}, P_{\mathrm{c}}, P_{\mathrm{d}}, W, Y+W T, Z\right)$

\section{Empirical Model}

Using the household utility function (Eq. 3.1), IAP interventions targeting emission abatement can reduce health costs, reduce the effects of respiratory diseases and other related health problems, and increase human productivity which is considered welfare improving. These interventions

$\mathcal{L}=U[X, L, I(B, C, D, Z)]+\lambda\left[Y+W(T-L)-W \propto I(B, C, D, Z)-\left(X+P_{\mathrm{b}} B+P_{\mathrm{c}} C+P_{\mathrm{d}} D\right)\right]$

The first-order conditions are shown in Eqs. (3.6a), (3.6b), (3.6c), (3.6d) and (3.6e).

$\frac{\partial U}{\partial X}=\lambda$

$\frac{\partial U}{\partial L}=\lambda W$ include adopting improved stoves, changing living environment characteristics, and switching to modern fuel use. In

the model, households are assumed to maximise their utility subject to indoor air quality function, time and budget constraints and other exogenous factors.

In this paper, three policy interventions are proposed and modelled: use of improved fuel stove appliance, change of living environment (use of chimney) and switching to modern energy. The empirical specifications for demand 
for improved stove appliance, chimney and modern energy, respectively are:

$S_{h}=\propto_{0}+\propto_{1} M_{h}+\propto_{2} N_{h}+\propto_{3} D_{h}+\varepsilon_{h}$

$L_{h}=\beta_{0}+\beta_{1} M_{h}+\beta_{2} D_{h}+\varepsilon_{h}$

$A_{h}=\gamma_{0}+\gamma_{1} P_{h}+\gamma_{2} N_{h}+\gamma_{3} D_{h}+\varepsilon_{h}$,

where $h=1 \ldots \mathrm{H}$ indexes households, $S, L$ and $A$ denote demand for improved fuel stove appliance, chimney and modern energy, respectively. $\alpha_{0}, \alpha_{1}, \alpha_{2}, \alpha_{3}, \beta_{0}, \beta_{1}, \beta_{2}$, and $\gamma_{0}, \gamma_{1}, \gamma_{2}, \gamma_{3}$ are coefficients to be estimated; $P_{h}$, a vector of fuel stove appliance (traditional stove, improved stove, ordinary jiko, improved jiko, kerosene stove, gas cooker and electric cooker); $M_{h}$, a vector of alternative fuel types (firewood, charcoal, kerosene, LPG and electricity); $N_{h}$, a vector of living environment (type of dwelling, kitchen location and presence of chimney); $D_{h}$, a vector of socio-economic variables (age, education levels, employment, households size and gender); and $\varepsilon_{h}$, the error term.

Estimating the outcome (event) of Eqs. (3.11), (3.12) and (3.13) using ordinary least square (OLS), results in sample selection bias. Sample selection bias or the problem of selectivity bias occurs when characteristics that influence the sample selection also influence the event or the outcome equation (Puhani 2000). When OLS is used, the assumption made is that the sample is chosen randomly from the whole population. The outcome equations violate the assumptions of OLS: first, the sample used to analyse the event represents a fraction of the whole population and second, the sample is not randomly selected.

The study utilises data sourced from a national household survey which is here referred to as the sample. Because the households in this sample have not been selected based on the dependent variables (as outlined in Eqs. 3.11, 3.12 and 3.13), a new sub-sample that is non-randomly selected is therefore constructed.

The outcome Eqs. (3.11), (3.12) and (3.13) may be subjected to sample selection because the event equations (household demand for improved fuel stove appliance, demand for chimney and demand for modern energy, respectively) are not representative of all households. This is because those who have not adopted correspondingly the use of improved stove appliance, use of chimney and use of modern fuel are not part of the new sub-sample for the outcome/event equation.

In addition, for each event or outcome equation, the decision on whether or not to adopt a specific intervention aimed at abating the levels of IAP is made by individual household, and those that have not adopted a particular intervention may constitute a self-selected sample. It may be possible that those who have not adopted a particular intervention (captured by missing data) might have been influenced by various factors, among them the high cost of adopting an intervention.

To address the problem of sample selection bias, the Heckman selection model is used to estimate Eqs. (3.11), (3.12) and (3.13) (Heckman 1974, 1979). The Heckman model corrects estimation biases as a result of non-random selected samples and allows information from the non-users of various IAP abatement interventions to improve the estimates of the parameters in the outcome (event) equation. The Heckman model also provides consistent, asymptotically efficient estimates, for all the parameters in the model. This model is implemented either using the two-stage approach (also known as the Heckit approach) or the maximum likelihood approach.

The first stage is the selection/participation model, where the probit regression model on the use or adoption of a particular intervention (use of improved stove appliance, use of chimney and use of modern fuel) is estimated. The second stage is an outcome/event model which involves correcting for self-selection, by incorporating a transformation of a specific adopted intervention selection probability as an additional explanatory variable in the outcome Eqs. (3.11), (3.12) and (3.13).

In the first stage of the Heckman selection model, households decide whether to adopt a particular intervention or not. There are three interventions that are analysed; adopting the use of improved stoves, use of chimney and use of modern energy. The first stage regression model is given in Eq. (3.14) and estimated using a probit model as defined in Eq. (3.15).

$V_{h}^{*}=X_{h}^{\prime} \beta+\mu_{h}$

$\operatorname{Pr}\left(V_{h}=1 \mid X\right)=\Phi\left(X_{h}^{\prime} \beta\right)$,

where $V_{h}$ is 1 , if the $h$ th household uses or adopts a particular intervention (where the latent variable $V_{h}^{*}>0$ shows the unobserved propensity of using a particular intervention) or 0 otherwise. $\beta$ is a vector of parameter to be estimated; and $X_{h}^{\prime}$,is a vector of explanatory variables which includes a set of alternative fuel stove appliances, set of fuel types alternatives, living environment characteristics and socio-economic variables. $\mu_{h}$ is the usual error term. $\Phi$ is the standard normal distribution. The maximum likelihood estimate of Eq. (3.15) is then used to compute the inverse Mills ratio ${ }^{3}$ for each household $h$, and is derived as:

$\lambda_{h}=\frac{\phi\left(X_{h}^{\prime} \beta\right)}{\Phi\left(X^{\prime}{ }_{h} \beta\right)}$,

\footnotetext{
3 The inverse of Mills ratio is the probability density function to the cumulative distribution function.
} 
where $\varphi$ and $\Phi$ are the standard normal density and cumulative distribution functions, respectively. The inverse Mills ratio is then used as an additional variable in the second stage. The expected demand models for improved fuel stove appliance, chimney and modern energy that were estimated are given as

$$
\begin{aligned}
& E\left(Z_{h} \mid V_{h}=1\right)=W_{h}^{\prime} \beta+\rho \sigma_{\varepsilon} \lambda\left(X^{\prime}{ }_{h} \beta\right) \\
& \quad \text { If } \rho \sigma_{\varepsilon}=\beta_{\lambda} \text { then Eq. }(3.17) \text { becomes } \\
& E\left(Z_{h} \mid V_{h}=1\right)=W_{h}^{\prime} \beta+\beta_{\lambda} \lambda\left(X^{\prime}{ }_{h} \beta\right),
\end{aligned}
$$

where $Z_{h}=W_{h}^{\prime} \beta+\varepsilon_{h}$ is observed if $V_{h}=1$ for households that choose to adopt an intervention, and 0 if not. $W_{h}^{\prime}$ and $X_{h}^{\prime}$ are vectors of covariates; $\beta$, a vector of parameters; $\rho$, is the correlation between unobserved determinants of propensity to adopt an intervention and unobserved determinants of outcome/event regression equation; $\varepsilon$ [obtained from the outcome model in Eq. (3.17)]; $\sigma_{\varepsilon}$, the standard of error $\varepsilon$; and $\lambda$, the inverse Mills ratio derived after estimating Eq. (3.16).

The coefficient for inverse Mills ratio $(\lambda)$ is used to show whether there is sample selection or not. When the coefficient for inverse Mills ratio is different from 0 (or the coefficient is statistically significant), it implies that there is sample selection bias (Karpaty and Kneller 2005). According to Khitarishvili (2009) the coefficient for inverse Mills ratio $(\lambda)$ is a product of $\rho$ times $\sigma$. In turn, $\rho$ is the correlation coefficient between $\varepsilon$ and $u$, and $\sigma$ is the standard deviation of $\varepsilon$.

The exclusion restriction is imposed in order to identify the parameters of this model (Greene 2003). Some variables included in the first stage (probit model) are excluded in the second stage (outcome/substantive model). However, the Heckman two-step estimators also allow the model to be identified without exclusion restrictions, in order to facilitate the model identification and address multicollinearity among explanatory variables and correlation between error terms. The use of valid exclusion restriction, the inverse mills ratio and explanatory vectors in the substantive equation are proposed (Bushway et al. 2007). Exclusion restrictions in current study are; log of income, traditional stove and middle and high household incomes categories for use of improved stove, chimney and modern energy, respectively.

According to Greene (2003), the marginal effects of the regressors on outcome variable, $Z_{h}$, in the observed sample consist of two components. There is the direct effect (from the outcome equation) on the mean of $Z_{h}$ which is $\beta$; and an indirect effect (from selection equation) through $\lambda_{h}$ for a particular independent variable, if it appears in the probability that $U_{h}^{*}$ is positive. From Eq. (3.18), the full effect of changes in a continuous regressor $\left(X_{h k}\right)$ that appears in both $X_{h}$ and $W_{h}$ on $Z_{h}$ is

$\frac{\partial E\left[Z_{h} \mid U_{h}^{*}>0\right]}{\partial X_{h k}}=\beta_{k}-\frac{\gamma_{k}}{\sigma_{u}} \beta_{\lambda} \delta_{h}$ where

$\delta_{h}=\lambda_{h}\left(\propto_{u}\right)\left[\lambda_{h}\left(\propto_{u}\right)-\propto_{u}\right]$ and $\propto_{u}=-\gamma^{\prime} W / \sigma_{u}$

Equation (3.19) is the conditional marginal effects of a continuous variable $\left(X_{h k}\right)$, while Eq. (3.21) is the conditional marginal effects of a discrete variable $\left(X_{h k}\right)$ going from 0 to 1 .

$E\left(\Delta Z_{h} \mid U_{h}=1\right)=\beta_{k}+\beta_{\lambda} \Delta \lambda$

where $\Delta \lambda=\frac{\phi\left(\gamma^{\prime} \bar{X}_{(1)} / \sigma_{u}\right)}{\Phi\left(\gamma^{\prime} \bar{X}_{(1)} / \sigma_{u}\right)}-\frac{\phi\left(\gamma^{\prime} \bar{X}_{(0)} / \sigma_{u}\right)}{\Phi\left(\gamma^{\prime} \bar{X}_{(0)} / \sigma_{u}\right)}$

$Z_{h}$ is the natural logarithm of expenditure on interventions, the conditional marginal effect of Eqs. (3.18) or (3.21) corresponding to a relative change in earnings. The estimated percentage change in earnings due to a unit increase in $\left(X_{h k}\right)$ is $[\exp (C)-1] 100$, where $C$ is the estimated value of the conditional marginal effect.

The unconditional relative marginal effect of a continuous variable $\left(X_{h k}\right)$ on the expected expenditure on interventions using Eq. (3.18) is:

$\frac{\partial}{\partial X_{h k}} \ln E\left(g_{h}\right)=\beta_{k}-\frac{\gamma_{k}}{\sigma_{u}} \beta_{\lambda} \delta_{h}+\left[\Phi\left(\frac{\gamma^{\prime} X_{h}}{\sigma_{u}}\right)\right]^{-1} \emptyset\left(\frac{\gamma^{\prime} X_{h}}{\sigma_{u}}\right) \frac{\gamma_{k}}{\sigma_{u}}$

The first part of the right-hand side $\left(e_{\mathrm{I}}\right)$ is the effect associated with a change in expenditure for those who have adopted interventions and the second part $\left(e_{\mathrm{II}}\right)$ is the effect associated with change in the probability of adopting an intervention.

Therefore, the percentage change in earnings due to a unit increase in $X_{h k}$ is $\left[\exp \left(C e_{\mathrm{I}}+e_{\mathrm{II}}\right)-1\right] 100$. If $X_{h k}$ is a discrete variable, the unconditional marginal effect when moving from 0 to 1 is given as:

$\Delta \ln E\left(g_{h}\right)=\Delta \ln E\left(g_{h} \mid U_{h}^{*}>0\right)+\Delta \ln \Phi\left(-\alpha_{u}\right)$,

where the first part of the right-hand side $\left(e_{\mathrm{I}}\right)$ and the second part $\left(e_{\mathrm{II}}\right)$ are already defined above. However, Hoffmann and Kassouf (2005) argue that better estimates of marginal effects come from calculating the conditional and unconditional marginal effects when applying Heckman's procedure.

\section{Data and Description of Variables}

The data used for analysis are drawn from the Kenya Integrated Household Budget Survey (KIHBS) 2005/2006 (GoK 2006). KIHBS is the richest and comprehensive energy data source that depicts the current energy use patterns and socioeconomic status of households.

Three intervention models are estimated in Eqs. (3.11), (3.12) and (3.13). The dependent variables for these equations are in logarithmic form and capture the monthly 
expenditure or cost related to the use of improved stove, chimney and modern energy, respectively. Estimated house rent $^{4}$ was used as a proxy for chimney expenditures.

\section{Energy Used (IAP)}

This is the type of fuel used for cooking. It is represented by five dummy variables, each of which captures a particular type of household energy used. The types of household energy are firewood, charcoal, kerosene, LPG and electricity. This variable is equal to 1 , if a specific type of household energy is being used; and 0 , otherwise. Households using modern energy are also expected to automatically use modern fuel stoves.

\section{Fuel Stove Appliance (Appliance)}

This is the type of stove used to burn fuel. It is captured by eight dummy variables including traditional three stone stove (tradstove), improved (traditional stone) stove (imprstove) ordinary jiko (ordjiko), improved jiko (imprjiko), kerosene stove (kerostove), gas cooker (gascooker), electric cooker (eleccooker) and other stove (otherstove). When one fuel stove appliance is considered, it takes a value of 1 , while the other fuel stove appliance takes a value of 0 . Type of stove is likely to influence modifications of living environment such as introducing windows and chimney in dwellings. However, the type of stove already dictates the type of household energy used. Uptake of modern energy is conditioned to household ownership of modern clean and modern fuel stove appliance (Gebreegziabher et al. 2010).

\section{Type of Kitchen}

This is the place/area used for cooking and is captured by six dummy variables. They include: outdoor kitchen (outdoor kitchen), enclosed detached kitchen (encdet kitchen), enclosed attached kitchen (enc-ata), indoor without partition kitchen (indwout kitchen), indoor-with-partition kitchen (indwith kitchen) and kitchen floor (other kitchen). It takes the values 1 and 0 otherwise, when one type of kitchen is observed. It is expected that those who cook outside are unlikely to adopt any of the three interventions.

${ }^{4}$ If the house was rented, the amount paid as rent for the dwelling in Kenya shillings per month was used. Alternatively if the house was not rented, then an estimate of the amount that would have been received/paid out in Kenya shillings per month for the dwelling or one exactly like it was rented to another person was used.

\section{Chimney}

This is a type of ventilation captured by a dummy variable that takes the value 1, if presence of chimney is observed, and 0 , otherwise. Dwellings with chimneys are expected to have positive expenditures on house design modifications.

\section{Age of the Household Head}

This is the age of the household head in years. Younger household heads when compared to older household heads are more likely to adopt modern energy (Mekonnen and Kohlin 2008).

\section{Education}

This is the education level of the household head and is represented by four dummy variables each representing a specific level of education. They include: head with primary education (hdprims), head with secondary education (hdsec), head with graduate education (hdgrad) and head with no education (hdnosch). When one education level is considered, it takes a value of 1 , and 0 otherwise. It is expected that those who are educated are more concerned about their indoor air quality. Lack of education has contributed to low levels of adopting modern energy and improved stoves (Jack 2004; Schlag and Zuzarte 2008; Gebreegziabher et al. 2010; Pachauri et al. 2004; Chambwera 2004).

\section{Location (Location)}

This is the geographic location of the residence and is captured by a dummy variable which equals 1 for rural location, and 0 , if urban.

\section{Household Expenditure (Income)}

This is defined as the total amount spent by households per month. It is used as a proxy for income. Adoption of modern energy and improved fuel stove is influenced by level of household income (Gebreegziabher et al. 2010; Pachauri et al. 2004; Chambwera 2004; Jaggernath 2013).

\section{Household Size}

This is the total number of members in a given household. How a large or small household size influences adoption of IAP abatement interventions is an empirical question.

\section{Employment (Empy)}

This is a dummy variable that captures those household heads on paid employment. It takes the value 1 , when the 
household head is on a paid employment, and 0 , otherwise. Household heads on paid employment are expected to adopt avertive actions that reduce the level of IAP.

\section{Chimney Expenditures (Costchimney)}

This is defined as the total amount spent monthly on chimney by households. Chimney costs represent a portion of the total house cost which is captured by the amount paid as rent. The rent costs differ by type of dwelling, type of material used in constructing the wall, roof and the floor, total number of dwelling and habitable rooms among others. For the house owners, the amount received if the house was rented was used instead as rent. Chimney expenditures may also incorporate maintenance cost associated with occasional cleaning of the chimney. The rent per month is used as a proxy for chimney expenditures.

\section{Improved Stove Expenditures (Newstovecost)}

This is the total amount spent monthly on improved stoves by households. The use of improved stove/improved traditional stove which is an improvement of the traditional three stone fire is complemented by the use of firewood. ${ }^{5}$ Improved stove expenditure is captured by costs associated with firewood use.

\section{Modern Energy Expenditures (Costmodernfuels)}

This is the total amount spent monthly on modern energy by households. The modern energy expenditures constituted the costs associated with the supply of LPG and electricity use.

\section{Results and Discussion}

\section{Descriptive Statistics}

Table 2 presents the summary statistics for the various variables used in estimating the outcome and selection equation for the three interventions. Out of about 13,212 households, the use of improved stove, chimney and modern energy interventions have been adopted by 978,990 and 648 households, respectively. An estimate of $72 \%$ of households that adopted improved stove intervention use firewood, while only $51 \%$ of those who use firewood also use chimneys.

Majority (54\%) of the households dwell in bungalows. An approximate of $64 \%$ of households living in bungalows

\footnotetext{
${ }^{5}$ In Kenya the common improved stoves/improved traditional stoves are the Kuni mbili and the Multipurpose stove wood which costs about 8.7 (739.50) and 9.6 (816), respectively (Clough 2012).
}

have adopted the improved stove intervention, while 76 and $38 \%$ have adopted the use of chimney and modern household energy, respectively.

Among the educated households' heads, those with primary education (46\%) form the largest population. Fiftythree percent of household heads with primary education have each adopted the use of improved stove and chimney, while $48 \%$ have adopted the use of modern household energy intervention.

The rural location comprises about $64 \%$ of the total population. Among the rural population, 57, 75 and $68 \%$ use improved stove, chimney and modern household energy IAP abatement interventions, respectively.

Household's heads on paid employment represented about $69.4 \%$. Household's heads that are on paid employment use more than one intervention. Those using improved stove, chimney and modern energy interventions were 70.7, 71.9 and $76.1 \%$, respectively.

\section{Regression Results}

The results for the use of improved stove, chimney and modern household energy interventions are discussed in "Improved Stove Intervention", "Chimney Intervention" and "Modern Energy Intervention", respectively.

\section{Improved Stove Intervention}

Table 3 presents the results for improved stove intervention, Eq. (3.11). The table reports parameter estimates for improved stove expenditure equation, marginal effects of selection (probit) equation for adoption of improved stove, and conditional and unconditional marginal effects using Heckman two-stage method. The coefficient of inverse Mills ratio helps in detecting the presence or absence of sample selection. In this case, the coefficient of the inverse Mills ratio variable (lambda), obtained from the probit equation, was -6.802 and statistically significant at $1 \%$. This implies that there is sample selection bias whose effect is controlled by inclusion of the inverse Mills ratio.

The demand for improved stove intervention was proxied by household expenditures related to the use of improved stove. The first stage of the Heckman two-stage method is the selection model, which estimates the adopting drivers for improved stove intervention; and the second stage of the Heckman two-stage method is the outcome model, which estimates the demand for improved stove intervention.

Determinants for Adoption of Improved Stove The results on the determinants for adoption of improved stove are shown in Table 3 (see marginal effects for probit model column). The rural location variable was found to be negative and significant at $1 \%$ level, indicating that households 
Table 2 Descriptive statistics of variables explaining demand for IAP abatement interventions. Source: Authors computation based on KIHBS 2005/2006 (GoK 2006)

Variables

\begin{tabular}{|c|c|c|c|}
\hline Full sample & $\begin{array}{l}\text { Improved } \\
\text { stove } \\
\text { intervention } \\
\text { sample }\end{array}$ & $\begin{array}{l}\text { Chimney } \\
\text { intervention } \\
\text { sample }\end{array}$ & $\begin{array}{l}\text { Modern fuel } \\
\text { intervention } \\
\text { sample }\end{array}$ \\
\hline Mean & Mean & Mean & Mean \\
\hline
\end{tabular}

Type of household energy

Kerosene ( $=1$ if household energy used is kerosene/paraffin, 0 otherwise)

Electricity ( $=1$ if household energy used is electricity, 0 otherwise)

LPG ( $=1$ if household energy used is LPG, 0 otherwise)

Charcoal ( $=1$ if household energy used is charcoal, 0 otherwise)

Firewood (=1 if household energy used is firewood, 0 otherwise)

Type of appliance

Traditional stove ( $=1$ if appliance used is traditional stove, 0 otherwise)

Improved stove ( $=1$ if appliance used is improved stove, 0 otherwise)

Ordinary jiko ( $=1$ if appliance used is an ordinary jiko, 0 otherwise)

Improved jiko ( $=1$ if appliance used is improved jiko, 0 otherwise)

Kerosene jiko ( $=1$ if appliance used is kerosene jiko, 0 otherwise)

Gas cooker (=1 if appliance used is gas cooker, 0 otherwise)

Electric cooker ( $=1$ if appliance used is electric cooker, 0 otherwise)

Type of dwelling

Bungalow house ( $=1$ if dwelling is bungalow house, 0 otherwise)

Flat house ( $=1$ if dwelling is mansionette house, 0 otherwise)

Mansionette house ( $=1$ if dwelling is mansionette house, 0 otherwise)

Swahili house (=1 if dwelling is swahili house, 0 otherwise)

Shanty house ( $=1$ if dwelling is shanty house, 0 otherwise)

Manyatta house (=1 if dwelling is manyatta/traditional house, 0 otherwise)

Kitchen location

Outdoor ( $=1$ if kitchen location is outdoor, 0 otherwise)

Enclosed and detached ( $=1$ if kitchen location is enclosed and detached, 0 otherwise)

Enclosed and attached ( $=1$ if kitchen location is enclosed and attached, 0 otherwise)

Indoor with partition ( $=1$ if kitchen location is outdoor, 0 otherwise)

Indoor with partition ( $=1$ if kitchen location is outdoor, 0 otherwise)

Education

Head graduate ( $=1$ if education level completed is graduate, 0 otherwise)

Head secondary ( $=1$ if education level completed is secondary, 0 otherwise)

Head primary ( $=1$ if education level completed is primary, 0 otherwise)

Head with no education ( $=1$ if education level completed is graduate, 0 otherwise)

Other characteristics

Chimney ( $=1$ if there is presence of chimney, 0 otherwise)

Gender ( $=1$ if gender is female, 0 otherwise)

Head age

Head age square

Household size with less or equal to 5 members

Household size between 6 and 12 members

Household size between 13 and 29 members

Rural (=1 if residing in rural area, 0 otherwise)

Income

Improved stove expenditures per month

Modern fuels expenditures per month $\begin{array}{llllllll}12,989 & 0.1090 & 977 & 0.0727 & 980 & 0.1660 & 648 & 0.0000\end{array}$ $\begin{array}{lllllllll}12,989 & 0.0082 & 977 & 0.0010 & 980 & 0.0163 & 648 & 0.1640\end{array}$ $\begin{array}{lllllllll}12,989 & 0.0417 & 977 & 0.0205 & 980 & 0.0857 & 648 & 0.8360\end{array}$ $\begin{array}{lllllllll}12,989 & 0.1820 & 977 & 0.1740 & 980 & 0.2050 & 648 & 0.0000\end{array}$ $\begin{array}{lllllllll}12,989 & 0.6460 & 977 & 0.7190 & 980 & 0.5110 & 648 & 0.0000\end{array}$

$\begin{array}{lllllllll}12,989 & 0.5800 & 978 & 0 & 990 & 0.2090 & 640 & 0.1940\end{array}$ $\begin{array}{llllllllll}12,989 & 0.0753 & 978 & 1 & 990 & 0.1350 & 640 & 0.0328\end{array}$ $\begin{array}{lllllllll}12,989 & 0.1000 & 978 & 0 & 990 & 0.1720 & 640 & 0.1410\end{array}$ $\begin{array}{lllllllll}12,989 & 0.0859 & 978 & 0 & 990 & 0.1660 & 640 & 0.0938\end{array}$ $\begin{array}{lllllllll}12,989 & 0.1050 & 978 & 0 & 990 & 0.1150 & 640 & 0.3000\end{array}$ $\begin{array}{lllllllll}12,989 & 0.0402 & 978 & 0 & 990 & 0.1600 & 640 & 0.1940\end{array}$ $\begin{array}{lllllllll}12,989 & 0.0059 & 978 & 0 & 990 & 0.0394 & 640 & 0.0313\end{array}$

$\begin{array}{llllllll}12,989 & 0.5460 & 978 & 0.6380 & 990 & 0.7570 & 640 & 0.3800\end{array}$ $\begin{array}{lllllllll}12,989 & 0.0360 & 978 & 0.0020 & 990 & 0.0606 & 640 & 0.1550\end{array}$ $\begin{array}{lllllllll}12,989 & 0.0116 & 978 & 0.0020 & 990 & 0.0586 & 640 & 0.0750\end{array}$ $\begin{array}{lllllllll}12,989 & 0.1170 & 978 & 0.0348 & 990 & 0.0677 & 640 & 0.1810\end{array}$ $\begin{array}{llllllll}12,989 & 0.0399 & 978 & 0.0194 & 990 & 0.0050 & 640 & 0.1130\end{array}$ $\begin{array}{lllllllll}12,989 & 0.2090 & 978 & 0.2570 & 990 & 0.0121 & 640 & 0.0547\end{array}$

$\begin{array}{llllllll}12,991 & 0.1730 & 978 & 0.2380 & 990 & 0.0374 & 639 & 0.0579\end{array}$ $\begin{array}{lllllllll}12,991 & 0.3170 & 978 & 0.3430 & 990 & 0.1800 & 639 & 0.1280\end{array}$

$\begin{array}{llllllll}12,991 & 0.1170 & 978 & 0.0695 & 990 & 0.4650 & 639 & 0.2430\end{array}$

$\begin{array}{llllllll}12,991 & 0.2940 & 978 & 0.2600 & 990 & 0.1030 & 639 & 0.4270\end{array}$ $\begin{array}{lllllllll}12,991 & 0.0930 & 978 & 0.0900 & 990 & 0.2150 & 639 & 0.1380\end{array}$

$\begin{array}{llllllll}13,212 & 0.0098 & 196 & 0.0051 & 182 & 0.0000 & 120 & 0.0083\end{array}$

$\begin{array}{llllllll}13,212 & 0.1530 & 196 & 0.1530 & 182 & 0.0604 & 120 & 0.1000\end{array}$

$\begin{array}{lllllllll}13,212 & 0.4590 & 196 & 0.5260 & 182 & 0.5330 & 120 & 0.4750\end{array}$

$\begin{array}{lllllllll}13,212 & 0.0232 & 196 & 0.0102 & 182 & 0.0220 & 120 & 0.0167\end{array}$

$\begin{array}{lllllllll}12,988 & 0.0762 & 978 & 0.1370 & 990 & 1 & 640 & 0.1560\end{array}$

$\begin{array}{llllllll}13,212 & 0.2970 & 196 & 0.3470 & 182 & 0.2860 & 120 & 0.3500\end{array}$

$\begin{array}{llllllll}13,212 & 44 & 196 & 44 & 182 & 47 & 120 & 45\end{array}$

$\begin{array}{llllllll}13,212 & 2212 & 196 & 2196 & 182 & 2471 & 120 & 2217\end{array}$

$\begin{array}{lllllllll}66,725 & 0.1190 & 978 & 0.1100 & 990 & 0.1090 & 648 & 0.1000\end{array}$

$\begin{array}{lllllllll}66,725 & 0.0775 & 978 & 0.0900 & 990 & 0.0727 & 648 & 0.0849\end{array}$

$\begin{array}{lllllllll}66,725 & 0.0017 & 978 & 0.0000 & 990 & 0.0020 & 648 & 0.0000\end{array}$

$\begin{array}{lllllllll}13,158 & 0.6440 & 969 & 0.5700 & 987 & 0.7480 & 648 & 0.6760\end{array}$

$\begin{array}{llllllll}13,118 & 3602 & 977 & 4586 & 990 & 3396 & 648 & 4121\end{array}$

$\begin{array}{lllllllll}975 & 744 & 975 & 744 & 134 & 561.8 & 21 & 768.9\end{array}$

$\begin{array}{llllllll}646 & 689 & 21 & 769 & 100 & 766.9 & 646 & 688.7\end{array}$ 
Table 2 (continued)

\begin{tabular}{|c|c|c|c|c|c|c|c|c|}
\hline \multirow[t]{2}{*}{ Variables } & \multicolumn{2}{|c|}{ Full sample } & \multicolumn{2}{|c|}{$\begin{array}{l}\text { Improved } \\
\text { stove } \\
\text { intervention } \\
\text { sample }\end{array}$} & \multicolumn{2}{|c|}{$\begin{array}{l}\text { Chimney } \\
\text { intervention } \\
\text { sample }\end{array}$} & \multicolumn{2}{|c|}{$\begin{array}{l}\text { Modern fuel } \\
\text { intervention } \\
\text { sample }\end{array}$} \\
\hline & $\mathrm{N}$ & Mean & $\mathrm{N}$ & Mean & $\mathrm{N}$ & Mean & $\mathrm{N}$ & Mean \\
\hline Chimney expenditures per month & 964 & 13,158 & 130 & 3051 & 964 & 13,158 & 95 & 13,829 \\
\hline Employed (=1 if in employment, 0 otherwise) & 4303 & 0.6940 & 75 & 0.707 & 64 & 0.719 & 46 & 0.761 \\
\hline
\end{tabular}

Table 3 Heckman sample selection estimation results for improved stove intervention. Source: Authors computation based on KIHBS 2005/2006 (GoK 2006)

\begin{tabular}{|c|c|c|c|c|c|c|c|c|}
\hline \multirow[b]{2}{*}{ Charcoal (d) } & \multicolumn{2}{|c|}{$\begin{array}{l}\text { Improved stove expendi- } \\
\text { ture model }\end{array}$} & \multicolumn{2}{|c|}{$\begin{array}{l}\text { Marginal effects for } \\
\text { probit model }\end{array}$} & \multicolumn{2}{|c|}{$\begin{array}{l}\text { Conditional marginal } \\
\text { effects }\end{array}$} & \multicolumn{2}{|c|}{$\begin{array}{l}\text { Unconditional mar- } \\
\text { ginal effects }\end{array}$} \\
\hline & 0.219 & $(0.276)$ & -0.003 & $(0.005)$ & 0.040 & $(0.385)$ & -0.018 & $(0.048)$ \\
\hline Paraffin (d) & $0.725^{+}$ & $(0.407)$ & $-0.013^{+}$ & $(0.007)$ & 0.027 & $(0.565)$ & -0.074 & $(0.064)$ \\
\hline LPG (d) & 1.017 & $(0.677)$ & $-0.019^{+}$ & $(0.010)$ & -0.053 & $(0.946)$ & -0.110 & $(0.095)$ \\
\hline Electricity (d) & $3.754^{+}$ & $(1.917)$ & $-0.049 * *$ & $(0.011)$ & -0.787 & $(3.053)$ & $-0.291^{*}$ & $(0.127)$ \\
\hline Rural (d) & $1.026^{* *}$ & $(0.289)$ & $-0.023 * *$ & $(0.005)$ & -0.070 & $(0.356)$ & $-0.138^{*}$ & $(0.056)$ \\
\hline Chimney (d) & $-3.082 * *$ & $(0.631)$ & $0.092 * *$ & $(0.014)$ & 0.084 & $(0.725)$ & $0.547 * *$ & $(0.192)$ \\
\hline Enclosed detached kitchen (d) & $1.188^{* *}$ & $(0.334)$ & $-0.021 * *$ & $(0.005)$ & 0.045 & $(0.438)$ & $-0.123 *$ & $(0.059)$ \\
\hline Enclosed attached kitchen (d) & $3.401 * *$ & $(0.674)$ & $-0.046^{* *}$ & $(0.004)$ & 0.125 & $(0.820)$ & $-0.265^{* *}$ & $(0.096)$ \\
\hline Indoor without partition kitchen(d) & $1.261 * *$ & $(0.341)$ & $-0.020 * *$ & $(0.005)$ & 0.200 & $(0.453)$ & $-0.106^{+}$ & $(0.060)$ \\
\hline Indoor with partition kitchen (d) & $1.324 * *$ & $(0.468)$ & $-0.022 * *$ & $(0.006)$ & 0.009 & $(0.627)$ & $-0.131^{+}$ & $(0.068)$ \\
\hline Flat house $(d)$ & $6.555^{* *}$ & $(1.350)$ & $-0.059 * *$ & $(0.004)$ & -0.301 & $(2.023)$ & $-0.345^{* *}$ & $(0.125)$ \\
\hline Swahili house(d) & $3.321 * *$ & $(0.692)$ & $-0.047 * *$ & $(0.004)$ & -0.065 & $(0.839)$ & $-0.277 * *$ & $(0.097)$ \\
\hline Shanty house(d) & $1.950 * *$ & $(0.698)$ & $-0.033 * *$ & $(0.007)$ & -0.259 & $(0.952)$ & $-0.199 *$ & $(0.086)$ \\
\hline Other dwelling (d) & -0.430 & $(0.520)$ & -0.002 & $(0.010)$ & -0.509 & $(0.726)$ & -0.038 & $(0.087)$ \\
\hline Manyatta/tradition house (d) & -0.273 & $(0.263)$ & 0.002 & $(0.005)$ & -0.150 & $(0.366)$ & 0.005 & $(0.047)$ \\
\hline Mansionette house(d) & $6.941 * *$ & $(2.326)$ & $-0.056^{* *}$ & $(0.004)$ & -0.191 & $(3.390)$ & $-0.329 * *$ & $(0.123)$ \\
\hline Log income & & & $0.015 * *$ & $(0.002)$ & $0.748 * *$ & $(0.114)$ & $0.130 * *$ & $(0.038)$ \\
\hline Mills (lambda) & $-6.802 * *$ & $(1.082)$ & & & & & & \\
\hline $\mathrm{N}$ & 12,733 & & & & & & & \\
\hline Censored & 11,827 & & & & & & & \\
\hline Uncensored & 906 & & & & & & & \\
\hline Wald $\chi^{2}(25)$ & 37.22 & & & & & & & \\
\hline Prob. $>\chi^{2}$ & 0.0020 & & & & & & & \\
\hline
\end{tabular}

Marginal effects; Standard errors in parentheses

(d) for discrete change of dummy variable from 0 to 1

${ }^{+} \mathrm{p}<0.10, * \mathrm{p}<0.05, * * \mathrm{p}<0.01$

that live in rural areas were less likely to adopt an improved stove compared to those in urban areas. This result is similar to what is provided in the literature. It indicates that rural households, because of cultural factors such as food type, lifestyle, cooking habit, taste preferences, local cuisine, kitchen type, gender relations and fuel preferences, are less likely to adopt improved stoves (Barnes et al. 1993; Budds et al. 2001; Masera et al. 2000; Oudejans 2011). In addition, the socio-economic differences between urban and rural locations could explain why urban population is adopting improved stoves.

Presence of chimney variable had a positive coefficient significant at $1 \%$ level as expected. This means that households with chimneys had a higher likelihood of adopting improved stove than those without chimneys. However, a high proportion of households chimneys come from those 
who own traditional stove fuel appliance (20.9\%) compared to those with own improved stove fuel appliance (13.5\%).

The variables for enclosed detached, enclosed attached, indoor with partition and indoor without partition kitchen location had a negative coefficients and were significant at $1 \%$ level. This showed that households that cook indoors (whether in enclosed detached, enclosed attached, with partitioned or without partitioned) had a lower probability of adopting an improved stove than those cooking from outdoors. ITDG (2002) found that households are unwilling to adopt improved stoves. Those who cook indoors may do so to exacerbate the levels of smoke that acts as mosquito repellant and also provides warmth during cold seasons (ITDG, ibid).

The coefficients for flat, swahili, shanty and mansionette types of dwelling variables were negative and significant at $1 \%$ level. This implied a lower probability for adopting improved stove by households living in such dwelling types, compared to those in bungalows. This may be because of their social status which makes these households less associated with use of traditional fuels along with their complimentary stoves (i.e. traditional three stone fire and improved stoves), and be more associated with use of modern energy and fuel stove appliances. For example, only 1.3 and $8.7 \%$ of households used firewood in flat and swahili houses, respectively.

The coefficient for paraffin/kerosene and LPG variables was negative and significant at $10 \%$ level. This means that households that use such type of energy were less likely to adopt improved stove intervention relative to those that used firewood. Households that use paraffin/kerosene may be unwillingly to adopt improved stove because they want to maintain an already attained social economic status. According to Masera et al. (2000) those households with such modern technology are considered prosperous.

Income variable had a positive coefficient as expected and was significant at $1 \%$ level. This implied that households with high income are more likely to adopt improved stove expenditures. Income was identified as an important factor for adoption of improved stove by Jaggernath (2013). According to literature, as income increases, households are likely to adopt better fuels and fuel stove appliance technologies.

Determinants for Improved Stove Expenditures The estimation results for log of improved stove expenditure model forms the second stage of the Heckman two-stage method. The estimated results for the demand of improved stove intervention are shown in Table 3 (see improved stove expenditure model column). The demand is proxied by household expenditures associated with the use of improved stove.
Rural location, paraffin/kerosene, electricity, enclosed detached, enclosed attached, indoor with partition and indoor without partition kitchen locations, flat, swahili, shanty and mansionette types of dwelling variables had positive significant coefficients while the presence of chimney had a negative significant coefficient.

The coefficients for paraffin/kerosene and electricity variables were positive and significant at $10 \%$. This means that households who use paraffin/kerosene or electricity had higher expenditures relative to household who use firewood. The use of improved stove as earlier indicated is complemented by use of firewood. It could be that those households who use either electricity or kerosene in addition to firewood are considered to have high incomes and this could explain why they have higher improved stove expenditures compared to those households who use firewood alone. In this case, the use of firewood is considered a normal good (an increase in income causes an increase in demand and vice versa).

The coefficient for indoor cooking location variables (enclosed attached, enclosed detached, indoors with partition and indoors without partition) was positive and significant at $1 \%$ level. This means that households cooking indoors had higher improved stove expenditures than household who cooked outdoor. Given that the use of improved stove intervention is supplemented by use of firewood. It could be that households who cook from indoors use more firewood compared to those who cook outdoors as a result of other factors such as speed of combustion.

The swahili, shanty, flat and mansionette dwelling variables had positive coefficients significant at $1 \%$ level. This means that households living in such dwelling had higher improved stove expenditures than household who dwell in bungalow house. The expenditures may be high, especially where firewood fuels are purchased compared to where there are zero/no costs as a result of using free firewood. It could be that households who dwell in the swahili, shanty, flat and mansionette are located in the urban areas where firewood fuels are purchased compared to those who dwell in bungalow houses (who are mainly located in rural areas with possibility of free access to firewood). For instance, in this study, the bungalow house is the main type of dwelling among rural households (56\%). Only $4 \%$ of flat and shanty house, $1 \%$ of mansionette house and $12 \%$ of swahili house are located in rural areas.

The variable for presence of chimney had negative coefficient and was significant at $1 \%$ level. This means that households who use chimney intervention had lower improved stove expenditures than household who do not use chimney intervention. It could be that the use of chimney and the use of improved stove interventions are more of substitute products. For instance it may mean that when income increases to a certain level, the use of chimney dominates that of improved stove intervention. In this case it could be that 
households who had achieved a particular level of income were more able to substitute the use of improved stove for chimney and this may explain the observed low expenditures for improved stove interventions.

The exclusion restriction variables are expected to affect adoption of improved stoves but not expenditure on improved stoves. The exclusion restriction variable appears in the adoption of improved stove (selection) equation of the Heckman model as an instrument for correcting sample selection (Puhani 2000). In this case, the log of income, which was the exclusion restriction, was significant at $1 \%$ implying that income affects the adoption of improved stove, but not the expenditure on improved stoves.

Table 3 also indicates the conditional and unconditional marginal effects of various explanatory variables, after carrying out the Heckman two-stage method for improved stove. Conditional marginal effects are based on the household sample of those who adopt improved stoves, while unconditional marginal effects are based on the total household sample of those who do and do not adopt improved stove. The conditional and unconditional marginal effects for both discrete and continuous regressors appearing in both outcome and selection equations can be obtained.

Explanation is similar for both continuous and discrete variables. For example, the traditional house variable, considering all explanatory variables at their mean value, a unit increase in traditional house will lead to a $27.3 \%$ drop in improved stove expenditures, for those who use improved stove; and a $0.155 \%^{7}$ increase in the proportion of households that adopt improved stove intervention. This corresponds to a $31.2 \%{ }^{8}$ fall in total improved stove expenditures.

\section{Chimney Intervention}

Table 4 reports the results for chimney intervention as shown in Eq. (3.12). The table summarises parameter estimates for chimney expenditure equation, marginal effects of selection (probit) equation for adoption of improved stove, and conditional and unconditional marginal effects of using Heckman two-stage method. The coefficient of inverse Mills (lambda), obtained from the probit equation, was -1.888 and was statistically significant at $10 \%$ level. This meant that there

\footnotetext{
${ }^{6}$ The coefficient for traditional/manyatta house from the improved stove expenditure model.

7 The differences between unconditional and conditional marginal effects for traditional/manyatta coefficients.

8 The sum of the differences between unconditional and conditional marginal effects for traditional/manyatta house coefficients, the difference between marginal effects for probit model and conditional marginal effects for traditional/manyatta house coefficients, and the coefficient for traditional/manyatta house from marginal effects for probit model.
}

is presence of sample selection bias, whose effect can be addressed by using the inverse Mills ratio.

The demand for chimney intervention was proxied by household expenditures related to the use of chimney. The first stage of the Heckman two-stage method is the selection model, which estimates the adopting drivers for chimney intervention; and the second stage of the Heckman two-stage method is the outcome model, which estimates the demand for chimney intervention.

Determinants for Adoption of Chimney The results on the determinants for adoption of chimney are shown in Table 4 (see marginal effects for probit model column). Rural location variable had a positive and statistically significant coefficient at $1 \%$ level. This implied that living in a rural location increases the likelihood of adopting chimney intervention compared to an urban one. In rural areas, the main type of dwelling is the bungalow which accounts for $56.3 \%$, followed by traditional and swahili dwellings with 18.9 and $12.1 \%$, respectively. Flat, shanty and mansionette houses account for 3.8, 3.7 and $1.03 \%$, respectively. The design factors for bungalows may allow easy erection of chimneys compared to flats and shanties. The percentage of bungalows with chimney was about $76 \%$ compared to swahili $(6.8 \%)$ and traditional (1.2\%) dwellings.

The variables for traditional stove, improved jiko and kerosene stove fuel appliances had negative coefficients and were significant at $1 \%$, except for improved jiko with $5 \%$ significance level. Those households which use this appliance are less likely to adopt the use of chimneys compared to those using electricity cookers. The use of chimney provides an opening that allows passage of smoke outside the dwelling. Absence of chimney, use of traditional stove and improved jiko fuel appliances imply presence of smoke indoors that may act as mosquito repellant.

The variables for flats and swahili houses had negative coefficient and were significant at $1 \%$. This showed that households that live in flats and swahili dwellings were less likely to adopt chimney interventions compared to those in traditional houses. Apart from cultural factors, the design of the type of dwelling and social economic status may play a key role in influencing whether or not chimney intervention is adopted. For instance, designs for flats and shanties do not, in most cases, consider erection of chimneys. In the case of swahili and traditional dwellings, the spacing left between the roof and the wall acts as a ventilation avenue that may limit the use of chimney. In fact, because of social economic status associated with flats and mansionettes, the use of clean and modern technologies implies less smoke, making the use of chimney unnecessary.

The coefficients for enclosed attached kitchen, enclosed detached kitchen and indoor with partition kitchen variables were positive and statistically significant at $1 \%$ level. This 
Table 4 Heckman sample selection estimation results for chimney intervention. Source: Authors computation based on KIHBS 2005/2006 (GoK 2006)

\begin{tabular}{|c|c|c|c|c|c|c|c|c|}
\hline \multirow[b]{2}{*}{ Rural (d) } & \multicolumn{2}{|c|}{$\begin{array}{l}\text { Chimney expenditure } \\
\text { model }\end{array}$} & \multicolumn{2}{|c|}{$\begin{array}{l}\text { Marginal effects probit } \\
\text { model }\end{array}$} & \multicolumn{2}{|c|}{$\begin{array}{l}\text { Conditional marginal } \\
\text { effects }\end{array}$} & \multicolumn{2}{|c|}{$\begin{array}{l}\text { Unconditional mar- } \\
\text { ginal effects }\end{array}$} \\
\hline & $-0.430 * *$ & $(0.109)$ & $0.021 * *$ & $(0.003)$ & 0.009 & $(0.130)$ & $0.150 * *$ & $(0.027)$ \\
\hline Log income & 0.033 & $(0.045)$ & -0.001 & $(0.001)$ & 0.021 & $(0.051)$ & -0.004 & $(0.010)$ \\
\hline Charcoal (d) & -0.011 & $(0.117)$ & -0.005 & $(0.004)$ & -0.121 & $(0.145)$ & -0.043 & $(0.032)$ \\
\hline Paraffin (d) & -0.107 & $(0.138)$ & 0.008 & $(0.006)$ & 0.046 & $(0.169)$ & 0.062 & $(0.046)$ \\
\hline LPG (d) & -0.124 & $(0.185)$ & 0.006 & $(0.008)$ & -0.013 & $(0.230)$ & 0.042 & $(0.062)$ \\
\hline Improved stove (d) & $-1.479 * *$ & $(0.190)$ & -0.0002 & $(0.007)$ & $-1.484 * *$ & $(0.239)$ & -0.058 & $(0.050)$ \\
\hline Ordinary jiko (d) & $-1.010^{* *}$ & $(0.163)$ & -0.009 & $(0.006)$ & $-1.206^{* *}$ & $(0.213)$ & $-0.103^{*}$ & $(0.042)$ \\
\hline Improved jiko (d) & $-0.866^{* *}$ & $(0.158)$ & $-0.012 *$ & $(0.005)$ & $-1.132 * *$ & $(0.210)$ & $-0.118 * *$ & $(0.039)$ \\
\hline Kerosene stove (d) & $-0.714 * *$ & $(0.166)$ & $-0.016^{* *}$ & $(0.005)$ & $-1.085^{* *}$ & $(0.218)$ & $-0.143 * *$ & $(0.038)$ \\
\hline Mansionette house(d) & $1.054 * *$ & $(0.254)$ & 0.022 & $(0.015)$ & $1.415^{* *}$ & $(0.320)$ & $0.245^{+}$ & $(0.137)$ \\
\hline Flat house (d) & $0.834 * *$ & $(0.197)$ & $-0.025 * *$ & $(0.004)$ & 0.146 & $(0.251)$ & $-0.174 * *$ & $(0.032)$ \\
\hline Swahili house (d) & $0.424 *$ & $(0.188)$ & $-0.029 * *$ & $(0.003)$ & $-0.372^{+}$ & $(0.223)$ & $-0.215^{* *}$ & $(0.028)$ \\
\hline Other dwelling (d) & -0.216 & $(0.226)$ & -0.007 & $(0.007)$ & -0.365 & $(0.276)$ & -0.062 & $(0.053)$ \\
\hline Enclosed detached kitchen (d) & $-0.407^{+}$ & $(0.221)$ & $0.054 * *$ & $(0.009)$ & $0.461^{+}$ & $(0.256)$ & $0.412 * *$ & $(0.079)$ \\
\hline Enclosed attached kitchen (d) & $-1.354 * *$ & $(0.347)$ & $0.274 * *$ & $(0.024)$ & $0.830^{*}$ & $(0.367)$ & $2.175^{* *}$ & $(0.227)$ \\
\hline Indoor without partition kitchen (d) & $-0.395^{+}$ & $(0.219)$ & 0.001 & $(0.007)$ & -0.373 & $(0.261)$ & -0.006 & $(0.057)$ \\
\hline Indoor with partition kitchen (d) & $-0.808 * *$ & $(0.295)$ & $0.156^{* *}$ & $(0.020)$ & $0.729 *$ & $(0.321)$ & $1.243 * *$ & $(0.187)$ \\
\hline Traditional stove (d) & & & $-0.091 * *$ & $(0.010)$ & $-1.478 * *$ & $(0.125)$ & $-0.751 * *$ & $(0.094)$ \\
\hline Mills (lambda) & $-1.888 * *$ & $(0.225)$ & & & & & & \\
\hline $\mathrm{N}$ & 12,793 & & & & & & & \\
\hline Censored & 12,793 & & & & & & & \\
\hline Uncensored & 11,842 & & & & & & & \\
\hline Wald $\chi^{2}(17)$ & 202.64 & & & & & & & \\
\hline Prob. $>\chi^{2}$ & 0.0000 & & & & & & & \\
\hline
\end{tabular}

Marginal effects; Standard errors in parentheses

(d) for discrete change of dummy variable from 0 to 1

${ }^{+} \mathrm{p}<0.10, * \mathrm{p}<0.05, * * \mathrm{p}<0.01$

means that cooking in these areas increases the probability of adopting chimney intervention. It may be possible that households that cook indoors and those that cook in enclosed kitchens may have bungalows as the main type of dwelling. About $62 \%$ of households that cook indoors and in enclosed kitchen live in bungalows. As discussed earlier, those that live in bungalows are more likely to have erected a chimney, explaining their higher likelihood to adopt the chimney intervention.

Determinants for Chimney Intervention Expenditures The estimation results of chimney intervention expenditure equation are reported in Table 4 (see chimney expenditure column). The variables for improved stove, ordinary jiko, improved jiko, kerosene stove and traditional stove type of fuel appliance had a negative coefficient and were also statistically significant at $1 \%$. This means that households who use improved stove, ordinary jiko, improved jiko and kerosene stove had lower chimney expenditures than house- hold who use electric cooker. The type of dwelling (which captures wealth) may explain why households who used improved stove, ordinary jiko, improved jiko and kerosene stove had lower expenditures than those who used electric cooker. It could be that the high chimney expenditures among households who use electric cooker are observed by wealthy households who mainly dwell in bungalow, flat and mansionettes houses.

The variables for mansionettes and flats dwellings had a positive coefficient and were significant at $1 \%$ level. The swahili dwelling also had a positive coefficient and was significant at 5\% level. This implies that households who dwell in mansionettes, flats and swahili type of dwellings had higher chimney expenditures than household who dwell in bungalow. As explained earlier, the limited use of chimneys may be attributed to the design aspects of the dwelling type. It may be difficult and costly to incorporate the chimney detail, especially in mansionettes, flats and swahili 
houses and this could explain why they have higher chimney expenditures.

The coefficients for households that cook indoors were all negative. The variables for enclosed detached and indoor without partition kitchen were significant at $10 \%$ level, while enclosed attached and indoor with partition kitchen were significant at $1 \%$ level. This may mean that household who cook from indoor kitchen had lower expenditures relative to those households who cook outdoors. The reason could be that it may be easier and cheaper to erect a chimney for an indoor kitchen than outdoor kitchen and this may explain why households who cook from an indoor kitchen had lower expenditures than those who cooked outdoors.

The coefficient for rural location variable was negative and significant at $1 \%$ level. This implied that household in rural areas had low chimney expenditures than households in urban areas. The low chimney expenditures among households in rural areas could be because of either the costs incurred in constructing a dwelling unit erected with chimney are lower or the demand for such dwelling units is low. The exclusion restriction variable in the model is the traditional stove, which was found to be significant at $1 \%$ level. This implies that the traditional stove is expected to affect adoption of chimney, but not expenditures on chimney.

Table 4 provides the conditional and unconditional marginal effects of various explanatory variables, after carrying out the Heckman two-stage method. Interpretations of both discrete and continuous variables follow similar explanations as done earlier in "Improved Stove Intervention".

\section{Modern Energy Intervention}

Table 5 reports the results for modern energy intervention. The table presents parameter estimates for modern energy expenditure equation, marginal effects of selection (probit) equation for adoption of modern energy, and conditional and unconditional marginal effects of using Heckman twostage method.

The coefficient of the inverse Mills ratio variable $(-5.703)$, obtained from the probit equation, is statistically significant. As earlier explained, the significance implies that there is a sample selection, and inclusion of the inverse Mills ratio is important to avoid sample selection bias.

Determinants for Adoption of Modern Energy The results on the determinants for adoption of modern energy are shown in Table 5 (see marginal effects for probit model column).

Different types of fuel stove appliances were found to be significant. Ownership of ordinary jiko, improved jiko, kerosene stove, gas cooker and electricity cooker, each, had a positive coefficient and they were all significant at $1 \%$ level. This showed that households that owned ordinary jiko, improved jiko, kerosene stove, gas cooker and electricity cooker had a higher probability of adopting modern energy compared to traditional stoves; as expected. Due to complementarity between the type of fuel and stove, adoption of one influences the use of the other. In this case, adoption of ordinary jiko, improved jiko, kerosene stove, gas cooker and electricity cooker acted to promote the use of modern energy. However, the coefficients for electricity cooker $(0.170)$ and gas cooker $(0.138)$ were higher, followed by kerosene stove (0.077), ordinary jiko (0.040) and improved jiko (0.028). Similar results were also obtained by Gebreegziabher et al. (2010).

The coefficients for enclosed attached and indoor without partition kitchen were positive and significant at 5 and $1 \%$ level, respectively. This implied that households that cook from enclosed attached kitchen and indoor without partition kitchen, are more likely to adopt modern energy compared to those who cooked from outside. About $42 \%$ of the households that cook from indoor without partition kitchen and $24 \%$ of the households who cook from enclosed attached kitchen made use of modern energy. The adoption of modern energy may also be explained by usage/ownership of modern fuel appliance. For example, $49 \%$ of households cooked in enclosed attached kitchen used modern energy (gas cooker and electricity cooker), compared to $18 \%$ of households that cooked indoors without partition.

The type of dwelling such as flats, mansionettes, swahili and shanty dwellings had positive coefficients and were significant at $1 \%$ level. This means that households living in flats, mansionettes, swahili and shanties had a higher likelihood of adopting modern energy when to those who live in bungalows. The coefficient for mansionette was high at 0.082 , followed by shanty (0.075), flat $(0.045)$, swahili $(0.015)$ and manyatta $(-0.011)$. The high coefficient for shanty type of dwelling may be explained by high proportion of households using modern fuel at about $11.3 \%$, compared to $3.6 \%$ of households using traditional fuels. The high levels of modern energy adoption for flats and mansionettes may be driven by social economic status.

Manyatta or traditional dwellings had a negative coefficient and were significant at $5 \%$ level. This means that living in traditional type of dwelling reduces the probability of adopting modern fuel interventions, compared to living in bungalows. Unobserved cultural factors for those living in traditional dwellings could be the reason behind low adoption of modern energy. These cultural factors include food type, lifestyle, cooking habit, taste preferences, local cuisine, gender relations and fuel preferences.

Rural location had a positive coefficient and was significant at 5\% level. This indicated that households in rural location were more likely to adopt modern energy intervention compared to urban ones. Being employed implies having access to disposable income for acquisition of modern fuel 
Table 5 Heckman sample selection estimation results for modern energy intervention. Source: Authors computation based on KIHBS 2005/2006 (GoK 2006)

\begin{tabular}{|c|c|c|c|c|c|c|c|c|}
\hline \multirow[b]{2}{*}{ Improve stove (d) } & \multicolumn{2}{|c|}{$\begin{array}{l}\text { Modern energy expendi- } \\
\text { tures }\end{array}$} & \multicolumn{2}{|c|}{$\begin{array}{l}\text { Marginal effects for } \\
\text { probit model }\end{array}$} & \multicolumn{2}{|c|}{$\begin{array}{l}\text { Conditional marginal } \\
\text { effects }\end{array}$} & \multicolumn{2}{|c|}{$\begin{array}{l}\text { Unconditional } \\
\text { marginal effects }\end{array}$} \\
\hline & -0.311 & $(0.434)$ & 0.007 & $(0.008)$ & 0.174 & $(0.660)$ & 0.047 & $(0.067)$ \\
\hline Ordinary jiko (d) & $-1.737 * *$ & $(0.522)$ & $0.040 * *$ & $(0.009)$ & 0.383 & $(0.640)$ & $0.255^{*}$ & $(0.108)$ \\
\hline Improved jiko (d) & $-1.542 * *$ & $(0.484)$ & $0.028 * *$ & (0.009) & 0.069 & $(0.633)$ & $0.167^{+}$ & $(0.092)$ \\
\hline Kerosene stove (d) & $-3.074 * *$ & $(0.713)$ & $0.077 * *$ & $(0.013)$ & 0.309 & $(0.797)$ & $0.477 * *$ & $(0.168)$ \\
\hline Gas cooker $(d)$ & $-4.125^{* *}$ & $(0.945)$ & $0.138 * *$ & $(0.023)$ & 0.461 & $(1.035)$ & $0.876^{* *}$ & $(0.291)$ \\
\hline Electric cooker (d) & $-4.673 * *$ & $(1.255)$ & $0.170 * *$ & $(0.048)$ & 0.335 & $(1.474)$ & $1.056^{*}$ & $(0.527)$ \\
\hline Chimney (d) & -0.361 & $(0.371)$ & 0.005 & $(0.005)$ & 0.015 & $(0.517)$ & 0.032 & $(0.047)$ \\
\hline Enclosed detached kitchen (d) & -0.425 & $(0.369)$ & 0.006 & $(0.006)$ & -0.015 & $(0.557)$ & 0.032 & $(0.050)$ \\
\hline Enclosed attached kitchen (d) & $-1.530 * *$ & $(0.487)$ & $0.023 *$ & $(0.009)$ & -0.157 & $(0.663)$ & 0.124 & $(0.086)$ \\
\hline Indoor without partition kitchen (d) & $-1.513^{* *}$ & $(0.418)$ & $0.017 * *$ & $(0.007)$ & -0.362 & $(0.580)$ & 0.085 & $(0.062)$ \\
\hline Indoor with partition kitchen (d) & $-1.298 * *$ & $(0.468)$ & 0.012 & $(0.008)$ & -0.501 & $(0.666)$ & 0.051 & $(0.069)$ \\
\hline Flat house $(\mathrm{d})$ & $-1.922 * *$ & $(0.560)$ & $0.045 * *$ & $(0.011)$ & 0.305 & $(0.686)$ & $0.282 *$ & $(0.128)$ \\
\hline Mansionette house(d) & $-2.826^{* *}$ & $(0.841)$ & $0.082 * *$ & $(0.024)$ & 0.475 & $(1.028)$ & $0.533^{*}$ & $(0.262)$ \\
\hline Swahili house (d) & $-0.716^{*}$ & $(0.343)$ & $0.015^{* *}$ & $(0.006)$ & 0.252 & $(0.465)$ & $0.098^{+}$ & $(0.056)$ \\
\hline Shanty house (d) & $-2.663 * *$ & $(0.703)$ & $0.075^{* *}$ & $(0.015)$ & 0.510 & $(0.807)$ & $0.488 * *$ & $(0.184)$ \\
\hline Manyatta house (d) & $1.097 * *$ & $(0.356)$ & $-0.011^{*}$ & $(0.004)$ & 0.152 & $(0.543)$ & -0.063 & $(0.043)$ \\
\hline Other dwelling (d) & -0.015 & $(0.497)$ & 0.001 & $(0.007)$ & 0.040 & $(0.719)$ & 0.006 & $(0.059)$ \\
\hline Rural (d) & -0.336 & $(0.238)$ & $0.007 *$ & $(0.003)$ & 0.178 & $(0.330)$ & 0.044 & $(0.028)$ \\
\hline Middle income & & & $0.164 * *$ & $(0.055)$ & & & & \\
\hline High income & & & $0.301 * *$ & $(0.054)$ & & & & \\
\hline Mills (lambda) & $-5.703 * *$ & $(1.022)$ & & & & & & \\
\hline $\mathrm{N}$ & 12,901 & & & & & & & \\
\hline Censored & 12,295 & & & & & & & \\
\hline Uncensored & 606 & & & & & & & \\
\hline Wald $\chi^{2}(8)$ & 31.16 & & & & & & & \\
\hline prob. $>\chi^{2}$ & 0.0276 & & & & & & & \\
\hline
\end{tabular}

Marginal effects; Standard errors in parentheses

(d) for discrete change of dummy variable from 0 to 1

${ }^{+} \mathrm{p}<0.10, * \mathrm{p}<0.05, * * \mathrm{p}<0.01$

and fuel stove appliances. In this case, the rural households formed a larger proportion of people who are employed, with $66 \%$.

The coefficient for middle- and upper-income households was positive and significant at $1 \%$. Therefore, when compared to the low-income households, those households with middle and high income are more likely to adopt modern energy as hypothesised. Similar results were achieved by Gebreegziabher et al. (2010); Pachauri et al. (2004); Chambwera (2004); Jaggernath (2013).

Determinants for Modern Energy Intervention Expenditure The estimation results of modern energy expenditure equation are reported in Table 5 (see modern energy expenditure column). The coefficient for enclosed attached, indoor without partition and indoor with partition kitchen had negative coefficients and were significant at $1 \%$ level.
This implies that households who cook from either enclosed attached kitchen, indoor without partition kitchen or indoor with partition kitchen had lower modern energy expenditures than households who cook from outdoors. It could be that household who cook indoors are more likely to use modern energy than those who cook outdoors. About 13, 24 and $43 \%$ of households cooking in enclosed attached kitchen, indoor without partition kitchen and indoor with partition kitchen, respectively, were observed to be using modern energy compared to $6 \%$ of those who cooked from outdoors. This may suggest that households that cook from such types of kitchen and who use modern energy may in turn benefit from lower modern fuel expenditures.

The coefficient for flats, mansionettes, swahili and shanty dwellings each had a negative coefficient and was significant at $1 \%$ level, except for swahili dwelling which had 5\% significance level. This implies that households who live in 
flats, mansionettes, swahili and shanties houses had lower modern energy expenditures than a bungalow house. Cultural factors such as food type, taste and fuel preferences, cooking habits and local cuisine could be the reason whether or not modern energy is adopted, hence influencing the level of modern energy expenditures. It is more likely for the rural households to observe their culture than the urban households. Among the households who lived in rural areas, majority lived in bungalow houses (56\%) compared to only $4 \%$ of households who lived in flat and shanty house, $1 \%$ of households who lived in mansionette house and $12 \%$ of households who lived in swahili house are located in rural areas. It could be that due to cultural factors, when compared to households who live in bungalows, those households who live in mansionettes, flats, swahili and shanty dwellings are more likely to adopt modern energy that translates to lower modern fuel expenditures.

The negative coefficients for the type of fuel stove appliance like the use of ordinary jiko, improved jiko, kerosene stove, gas cooker and electric cooker implied that households who use ordinary jiko, improved jiko, kerosene stove, gas cooker and electric cooker have lower modern energy expenditures than households who use traditional stoves. It could be that the use of ordinary jiko, improved jiko, kerosene stove, gas cooker and electric cooker are considered to be more efficient (less fuel less is used) compared to traditional fuels.

The exclusion restriction variables in the model are the income quintiles. Being in the middle- and high-income quintiles influences the adoption of modern energy but not expenditures on modern fuel interventions.

\section{Conclusions and Policy Implications}

\section{Conclusions}

The results from the Heckman two-stage method indicate that factors driving adoption of improved stoves are the use of firewood, cooking outdoors, having a chimney, residing in a bungalow house, living in rural areas and having high incomes. Households who live in rural areas, those who use kerosene or electricity, those who cook indoors and those that dwell in swahili, shanties, flats or in mansionettes were likely to have higher improved stove expenditures while household who have chimney are more likely to have lower improved stove expenditures. The demand for improved stove interventions, therefore, was influenced by geographical location, type of household energy used, cooking place/ area, type of dwelling, income and whether or not households had a chimney.

Households in rural areas, those who use electric cooker, those who dwell in traditional houses and those who cooked from indoor with partition, enclosed attached and detached kitchen were more likely to adopt the chimney intervention.

Households who use improved stove, ordinary jiko, improved jiko or kerosene stove, those that cooked from indoor kitchen had lower chimney expenditures and those that reside in rural areas are more likely to have lower chimney expenditures. Households who dwell in mansionettes and flats houses are more likely to have higher chimney expenditures. The geographical location, type of dwelling, kitchen location, type of fuel appliance used were key factors influencing the demand for chimney interventions.

The selection of modern energy intervention was driven: by ownership of ordinary jiko, improved jiko, kerosene stove, gas cooker and electric cooker; by households who cook from enclosed attached and indoor without partition kitchen location; by households who live in flats, mansionettes, swahili and shanty dwellings; by households who live in rural areas; and by those having middle and high incomes.

Households who use ordinary jiko, improved jiko, kerosene stove, gas cooker or electric cooker; those who cook from either enclosed attached kitchen, indoor without partition kitchen or indoor with partition kitchen; and those who dwell in flat, mansionette, swahili and shanty houses have lower modern energy expenditures. Overall, the factors influencing demand for modern fuels are type of fuel stove appliance, cooking area, type of dwelling, geographical location and income.

\section{Policy Implications}

Presence of chimney aims at reducing the levels of IAP. The government should not only enhance the adoption of chimney but also encourage construction of dwellings with inbuilt chimney. Inbuilt chimney is simple and less costly to construct for bungalow type of house/dwelling and mansionette but are more complex and costly for mansionettes, flats and swahili houses. This also calls the attention of house design and developer experts to consider and integrate this aspect when targeting residential dwellings. The government can also provide conditions/requirement that enforces all residential houses constructed by developers incorporates a chimney before final approval of fit for habitat is issued to the developer. Proper ventilation should be encouraged among the households especially the use of chimney. This can be done through public awareness from various channels such as education in school, mass education on radios, internet, televisions, radios and posters among others.

Ownership of modern fuel appliances like gas cooker and electric cooker was a requirement for use of modern energy intervention; however, households did not adopt it. The reason for non-adoption was the high associated expenditures fueled by high market transactions costs (especially for rural households), low incomes and the type of dwelling. 
The government can enhance rural market access for both modern energy and fuel stove appliances. This can be done by strengthening local artisan and retailers to engage in production and sale of modern energy technologies. Engaging in such entrepreneurial activities provides households with income. Also, this will increase the market penetration of modern energy technologies and also with time it will reduce the cost of such technologies. The government could educate the poor on the selection and investments made on fuel stove appliance. Investments made, on type of fuel stove appliance, automatically dictates the type of energy used. Solar cooking has become an important energy source for cooking today and globally; however, because of data limitation, this study was not able to consider solar energy as part of the analysis. Therefore future research studies should consider incorporating solar energy as one of the key modern energy solutions for cooking.

The local community should be educated on simple principles of designing both the chimney and the improved stoves, while integrating the developed designs with their own culture. Integrating such technology with the local culture aims at empowering the local community by making them more entrepreneurial towards job creation and income generation.

\section{Areas of Future Research}

Solar is becoming one of the key modern sources of energy used for cooking among Kenya households. The study intended to analyse all the sources of energy used by households; however, analysis on solar energy was not done because of the limited sample available from the data source. It was difficult to make any meaningful analysis from the few respondents who used solar at that point of time. This study proposes future research studies on this subject be done especially those that consider solar adoption among households for cooking, lighting and heating.

\section{Compliance with Ethical Standards}

Conflict of interest On behalf of all authors, the corresponding author states that there is no conflict of interest.

\section{References}

Adhikari N (2012) Measuring the health benefits from reducing air pollution in Kathmandu Valley. SANDEE working paper, No. 69-12

Adol-Agyarko AO (2009) Household energy, coping strategies and health effects in the Bongo district of Ghana. (Ph.D. Paper). Kwame Nkrumah University of Science and Technology, Kumasi Adrianzén M (2010) Improved stove adoption, firewood consumption and housewives' health: evidence from the Peruvian Andes. http:// mitsloan.mit.edu/neudc/papers/paper_289.pdf. Accessed 06 Mar 2012
Baldwin S, Winiarski L (2005) Designing stoves with Baldwin and Winiarski. In: Bryden M (ed) Design principles for wood burning cook stoves. U.S. Environmental Protection Agency, Office of Air and Radiation, Washington, DC, pp 105-113

Ballard-Tremeer G, Mathee A (2000) Review of interventions to reduce the exposure of women and young children to indoor air pollution in developing countries. Paper prepared for US Agency for International Development (USAID) and World Health Organisation (WHO) Global Consultation, Health Impacts of Indoor Air Pollution and Household Energy in Developing Countries: Setting the Agenda for Action, May 3-4, Washington, DC

Barnes BR (2005) Interventions to reduce child exposure to indoor air pollution in developing countries: behavioural opportunities and research needs. Child Youth and Environ, 15(1):67-82

Barnes DF, Openshaw K, Smith K, Van der Plas R (1993) The design and diffusion of improved cooking stoves. World Bank Res Obs 8(2):119-141

Barnes DF, Openshaw K, Smith K, Van der Plas R (1994) What makes people cook with improved biomass stoves? A comparative international review of stove programmes. World Bank Technical Paper 242. World Bank and Loughborough (WELL), Washington, DC

Bates E, Doig A (2001) Personal communication. ITDG, Rugby

Brandt S, Hanemann M (2003) Valuing environmental health risk reductions to children. Paper presented at environmental protection agency workshop of valuation of children's health, Washington, DC

Budds J, Biran A, Rouse J (2001) A review of the health impacts of indoor air pollution and technical interventions for its reduction. Water and Environmental Health at London

Bushway S, Johnson B, Slocum L (2007) Is the magic still there? The use of the Heckman two-step correction for selection bias in criminology. J Quant Criminol 23:151-178

Chambwera M (2004) Economic analysis of urban fuelwood demand: the case of Harare in Zimbabwe. (Ph.D. Paper). Department of Environmental Sciences, Wageningen University

Clough L (2012) The improved cook stove sector in East Africa: experience from the developing energy enterprise programme (DEEP). GVEP International, London

Deloitte (2016) Kenya economic outlook. The story behind the numbers

Department for International Development-DFID (1999) Energy for the rural poor: guidance note. DFID Energy Department, London

Diaz E (2008) Impact of reducing indoor air pollution on women's health. Randomised exposure study of pollution indoors and respiratory effects (RESPIRE). University of Bergen, Norway

Duflo E, Greenstone M, Hanna R (2008) Indoor air pollution, health and economic well-being. Inst Veolia Environ 1:7-16

Edwards JH, Langpap C (2008) Fuel choice, indoor air pollution, and children's health. Tulane Economics, Working Paper Series, Oregon

Ezzati M (2002) The missing costs and benefits in the application of cost-benefit analysis to the evaluation of household level technology. Presented at the cost-benefit analysis dilemma: strategies and alternatives, October 1999, New Haven, CT. http://www.rff. org/ ezzati/Household-CBA.pdf. Accessed 15 Aug 2002

Ezzati M, Kammen DM (2002) The health impacts of exposure to indoor air pollution from solid fuels in developing countries: knowledge, gaps, and data needs. Environ Health Perspect 110(11):1057-1068

Gebreegziabher Z, Mekonnen A, Kassie M, Kohlin G (2010) Urban energy transition and technology adoption: the case of Tigray, Northern Ethiopia. Environment for development, discussion paper series. EFD DP 10-22 
Goldemberg J (2000) Rural energy in developing countries. Chapter 10 in UNDP world energy assessment: energy and the challenge of sustainability. UNDP, New York

Government of Kenya (GoK) (2006) Kenya integrated household budget survey. Kenya National Bureau of Statistics-KNBS, Nairobi

Government of Kenya (GoK) (2010) Kenya demographic and health survey. Kenya National Bureau of Statistics-KNBS, Nairobi

Greene WH (2003) Econometric analysis, 5th edn. Prentice Hall, Upper Saddle River

Grossman M (1972) On the concept of health capital and the demand for health. J Polit Econ 80(2):223-255

Gupta U (2006) Valuation of urban air pollution: a case study of Kanpur city in India. South Asian Network for Development and Environmental Economics, Kathmandu

Heckman JJ (1974) Shadow prices, market wages, and labour supply. Econometrica 42(4):479-694

Heckman JJ (1979) Sample selection bias as a specification error. Econometrica 47(1):153-162

Hiemstra-van der Horst G, Hovorka AJ (2008) Reassessing the "energy ladder': household energy use in Maun, Botswana. Energy Policy 36(9):3333-3344

Hoffmann R, Kassouf AL (2005) Deriving conditional and unconditional marginal effects in log earnings equations estimated by Heckman's procedure. Appl Econ 37(11):1303-1311

Hosier RH, Dowd J (1987) Household fuel choice in Zimbabwe. Res Energy 9:347-361

Hosier RH, Kipondya W (1993) Urban household energy use in Tanzania: prices, substitutes and poverty. Energy Policy 21:454-473

ITDG (2002) Reducing indoor air pollution in rural households in Kenya: working with communities to find solutions. ITDG smoke and health project, 1998-2001

Jack DW (2004) Household behaviour and energy demand: evidence from Peru. (Ph.D. Paper). Harvard University

Jaggernath J (2013) A socio-economic and spatial investigation into the health implication of air pollution in Richards Bay, KwaZuluNatal, South Africa. (Ph.D. Paper). University of KwaZulu-Natal

Jebaraj S, Iniyan S (2006) A review of energy models. Renew Sustain Energy Rev 10(4):281-311

Karpaty P, Kneller R (2005) Demonstration or congestion? Export spillovers in Sweden. Globalisation, productivity and technology. Research paper 2005/44, University of Nottingham

Khitarishvili T (2009) Explaining the gender wage gap in Georgia. The Levy Economics Institute of Bard College, Working Paper No. 577

Lambe F, Jürisoo M, Wanjiru H, Senyagwa J (2015) Bringing clean, safe, affordable cooking energy to households across Africa: an agenda for action, a new climate economy working paper, based on a background paper to the Africa progress panel 2015 report power, people, planet: seizing Africa's energy and climate opportunities. http://www.sei-international.org/publications?pid=2841

Lanto E, Leslie J (2006) Rocket mass heaters: superefficient woodstoves you can build. Coquille, OR: Cob Cottage Co. ISBN 978-0-9663738-3-7

Larson BA, Rosen S (2002) Understanding household demand for indoor air pollution control in developing countries. Soc Sci Med 55(4):571-584

Leach G (1992) The energy transition. Energy Policy 20(2):116-123

Masera O, Saatkamp B, Kammen D (2000) From linear fuel switching to multiple cooking strategies: a critique and alternative to the energy ladder model. World Dev 28(12):2083-2103

Mekonnen A, Kohlin G (2008) Determinants of household fuel choice in major cities in Ethiopia. Environmental for development, resources for future, discussion paper series 08-18

Oudejans J (2011) Stimulating the transition to low carbon cooking solutions in rural India. (Master's paper), University of Utrecht

Pachauri S, Mueller A, Kemmler A, Spreng D (2004) On measuring energy poverty in Indian households. World Dev 32(12):2083-2104

Pant KP (2007) Valuing interventions to reduce indoor air pollutionfuelwood, deforestation, and health in rural Nepal. Pak Rev 46(4 Part II):1169-1187

Puhani P (2000) The Heckman correction for sample selection and its critique. J Econ Surv 14(1):53-68

Schlag N, Zuzarte F (2008) Market barriers to clean cooking fuels in sub-Saharan Africa: a review of literature. Working paper, Stockholm Environment Institute

Smith KR (1987) Biofuels, air pollution, and health: a global review. New York, Plenum Press

Winiarski L (2005) Ten design principles. In: Bryden M (ed) Design principles for wood burning cook stoves. U.S. Environmental Protection Agency, Office of Air and Radiation, Washington, DC, pp 105-113

World Bank (2011) One goal, two paths: achieving universal access to modern energy in East Asia and the Pacific. World Bank. https:// openknowledge.worldbank.org/handle/10986/2354. License: CC BY 3.0 IGO

World Health Organisation (WHO) (2000) Guidelines for indoor air quality. Mimeo, Geneva

Zhang Y (2009) Household energy use, indoor air pollution, and health impacts in India: a welfare analysis. PhD thesis, University of Maryland

Zuk M, Rojas L, Blanco S, Serrano P, Cruz J, Angeles F, Tzintzun G, Armendariz C, Edwards RD, Johnson M, Riojas-Rodriguez H, Masera O (2006) The impact of improved wood-burning stoves on fine particulate matter concentrations in rural Mexican homes. J Expo Sci Environ Epidemiol 17(3):224-232 